\title{
Erminia Chiara CALABRESE, Robin BEAUMONT (dir.), «Chiismes politiques. Pouvoirs, engagements, imaginaires politiques chiites au XXI ${ }^{\mathrm{e}}$ siècle »
}

Revue des mondes musulmans et de la Méditerranée, 145, 2019, 324 p.

\section{Laurence Louër}

\section{(2) OpenEdition Journals}

Édition électronique

URL : http://journals.openedition.org/assr/57252

DOI : $10.4000 /$ assr.57252

ISSN : $1777-5825$

Éditeur

Éditions de l'EHESS

Édition imprimée

Date de publication : 31 décembre 2020

Pagination : 153-155

ISBN : 978-2-7132-2826-1

ISSN : 0335-5985

Référence électronique

Laurence Louër, «Erminia Chiara calabrese, Robin beaumont (dir.), «Chiismes politiques. Pouvoirs, engagements, imaginaires politiques chiites au xxie siècle » », Archives de sciences sociales des religions [En ligne], 192 | octobre-décembre 2020, mis en ligne le 31 décembre 2020, consulté le 22 janvier 2021. URL : http://journals.openedition.org/assr/57252 ; DOI : https://doi.org/10.4000/assr.57252

Ce document a été généré automatiquement le 22 janvier 2021.

() Archives de sciences sociales des religions 


\section{Erminia Chiara CALABRESE, Robin BEAUMONT (dir.), « Chiismes politiques. Pouvoirs, engagements, imaginaires politiques chiites au $\mathrm{XXI}^{\mathrm{e}}$ siècle »}

Revue des mondes musulmans et de la Méditerranée, 145, 2019, 324 p.

\section{Laurence Louër}

\section{RÉFÉRENCE}

Erminia Chiara CALABRESE, Robin BEAUMONT (dir.), «Chiismes politiques. Pouvoirs, engagements, imaginaires politiques chiites au XxI siècle ", Revue des mondes musulmans et de la Méditerranée, 145, 2019, 324 p.

1 Comme son titre l'indique, ce numéro a pour objectif d'analyser la diversité des usages politiques du chiisme. Le thème de la production de l'imaginaire politique est le principal fil conducteur qui relie entre eux les six articles. Sepideh Parsapajouh et Agnès Devictor s'intéressent au rôle de l'État iranien dans ce processus, dans deux contextes de violence extrême, la guerre Iran-Iraq (1980-1988) d'une part, l'intervention iranienne dans les guerres civiles en Iraq et en Syrie (depuis 2011) d'autre part. S. Parsapajouh analyse la confrontation entre religiosité d'État et religiosité individuelle par l'intermédiaire d'une ethnographie des usages de tombes de soldats morts pendant la guerre Iran-Iraq. Engagé dans une politique de patrimonialisation, l'État reconstruit les tombes sur un modèle standardisé, les transformant en des lieux de mémoire au sens où l'entend Pierre Nora, investies par le haut d'un sens collectif pour, en l'occurrence, non seulement forger une unique interprétation de la guerre Iran-Iraq mais aussi formater les perceptions de 
l'engagement militaire actuel en Syrie et en Iraq. Profondément affective, individuelle et personnalisée, la mémoire des familles des soldats est menacée d'effacement dans ce processus, suscitant colères individuelles mais aussi protestations collectives. Dans cette confrontation, l'État, qui a si bien su politiser la dévotion populaire chiite - et singulièrement le rapport à la mort - à des fins de mobilisation et de légitimation, voit celle-ci le déborder.

2 Consacré à l'analyse de l'imaginaire de guerre tel qu'il est véhiculé par un corpus d'images récoltées en Iran (films, séries, documentaires, imagerie des réseaux sociaux), l'article d'A. Devictor retravaille la question de ce que l'anthropologue américain Michael Fisher a appelé le "paradigme de Karbala ». Thème désormais classique de la littérature sur le chiisme, il fait référence à la manière dont les rituels de Ashura, durant lesquels les chiites commémorent chaque année le massacre de l'Imam Hussein par les armées du calife en 680 sur le site de Karbala, fournissent un cadre d'interprétation du réel qui demeure puissamment opératoire dans l'histoire politique moderne des communautés chiites. Longtemps célébré dans une perspective purement sotériologique, à partir des années 1960, le martyre d'Hussein a été réinterprété par l'islam politique chiite comme un acte exemplaire de rébellion absolue contre l'ordre politique injuste. Les "films de la Défense sacrée », qui portent sur la guerre avec l'Iraq et ont pour la plupart été projetés durant la guerre elle-même, s'inspirent directement des codes de la ta'ziyyeh, ces pièces de théâtre jouées durant l'Ashura qui racontent les différents épisodes de la bataille de Karbala. C'est pourquoi ces films, centrés sur le sacrifice volontaire pour la cause, se distinguent de l'iconographie occidentale de la guerre par la monstration de la violence exercée à l'encontre de ses propres troupes. La logique est la même pour l'iconographie des interventions iraniennes actuelles en Iraq et en Syrie. Mais, en raison du contexte intérieur et extérieur radicalement différent, le paradigme de Karbala est significativement reconfiguré. D'une part, le régime iranien doit faire face à une désaffection croissante de pans entiers de la population qui se traduit régulièrement par des protestations collectives. D'autre part, la guerre en Iraq et en Syrie n'est pas une guerre défensive mais une intervention extérieure dont le but est d'étendre l'influence régionale de l'Iran. Elle ne bénéficie pas de l'unanimité nationale qui a permis à l'Iran de résister à l'agression iraquienne au prix de centaines de milliers de morts. Dans ce contexte, l'iconographie retravaille la notion de minorité, centrale dans la perception que les chiites ont d'eux-mêmes (ils ne représentent au plus que $15 \%$ des musulmans) ainsi que dans le paradigme de Karbala. Dans la représentation des interventions extérieures, la minorité des justes n'est pas les chiites dans leur ensemble, ni même les Iraniens, mais l'ensemble de ceux qui participent et soutiennent ces opérations, y compris les étrangers, car la nouveauté est bien la mise en scène des combattants chiites libanais, iraquiens, syriens ou afghans qui peuplent les bataillons de l'Armée des gardiens de la révolution envoyés au front ou sont membres des milices locales qui les suppléent. Alors que les "films de la Défense sacrée » mêlaient nationalisme iranien et mystique chiite, l'imaginaire combattant des films de « la Défense des lieux saints » (c'est-à-dire les mausolées des figures sacrées du chiisme situés en Iraq et en Syrie) se projette ici dans une géographie religieuse transnationale.

Les textes de Nicolas Dot-Pouillard, Khalyla Aude Coëffic et Benedict Robin-D'Cruz se penchent sur la manière dont l'imaginaire politique chiite est alimenté par celui des mouvements politiques alliés. K. A. Coëffic analyse le travail de cadrage de la cause palestinienne et de la défense du régime syrien par le Hezbollah. Elle montre comment 
ce dernier a islamisé et sacralisé la lutte contre Israël en présentant comme un devoir religieux la libération de Jérusalem, lieu saint de l'islam, permettant de relégitimer une cause palestinienne qui tendait à perdre son attrait auprès des populations chiites, premières frappées par les représailles israéliennes contre la résistance palestinienne installée au Sud-Liban. L'autrice repère un processus similaire dans le cadrage de l'implication du Hezbollah dans la guerre en Syrie : il ne s'agit pas tant de venir au secours du régime syrien que de défendre le tombeau de Zaynab, sœur de l'Imam Hussein, figure héroïque et icône chiite dont le mausolée se trouve dans une banlieue de Damas.

4 Les textes de N. Dot-Pouillard et B. Robin-D'Cruz analysent, entre autres sujets, les effets des alliances entre l'islam politique chiite et les mouvements de gauche. N. DotPouillard formule l'idée d'un concordisme entre les deux courants. Dans le monde arabe, les partis communistes ont beaucoup recruté parmi les populations chiites dans les années 1950 et 1960. Ces communautés marginalisées ont été attirées par le discours promettant la revanche des faibles sur les puissants, suscitant une hybridation des imaginaires dans un contexte où les islamistes chiites poussaient à une réinterprétation révolutionnaire du mythe de Karbala. Les militants communistes n'ont pas seulement abondamment joué sur ces résonnances autour du thème de la révolution, ils ont également soutenu la révolution iranienne et passé diverses alliances avec les islamistes chiites qui sont toujours d'actualité puisque la plupart des organisations de gauche arabes soutiennent l'Iran et la Syrie contre Israël et l'Occident. L'auteur avance l'hypothèse de la production d'un "imaginaire néo-tiers-mondiste" dans lequel le concept de résistance s'est substitué à celui de révolution. Formulée au départ par le Hezbollah libanais, après qu'il eut abandonné son projet de révolution islamique pour se focaliser sur la résistance à l'occupation israélienne du Sud-Liban, la résistance à Israël est devenue pour la gauche et l'islam politique chiite une métonymie de la résistance globale à l'injustice.

5 L'article de B. Robin-D'Cruz éclaire un autre aspect de l'alliance entre chiisme politique et gauche, beaucoup plus contre-intuitif : l'hybridation entre messianisme et légitimité technocratique qui résulte de l'alliance tissée en 2016 entre la gauche iraquienne et le mouvement des Sadristes, dont le leader éponyme, Muqtada al-Sadr, est issu d'une prestigieuse famille cléricale. Outre qu'elle a débouché sur une impressionnante victoire électorale en 2018, l'alliance a poussé à une professionnalisation accrue des Sadristes par un phénomène de division du travail et de diversification du leadership qui a permis l'émergence de leaders laïcs dont la légitimité repose sur leur formation et leurs compétences techniques. La question centrale posée par l'auteur est la manière dont l'hybridation des légitimités influence l'exercice de l'autorité au sein du mouvement sadriste. Il s'interroge notamment sur les limites du processus de sécularisation dans un contexte où, en raison de la centralité de Muqtada al-Sadr, la dimension messianique semble irréductible.

6 En contrepoint des articles sur l'islam politique chiite, l'article de Vincent Geisser se penche sur le répertoire et les acteurs de l'anti-chiisme dans le champ musulman français, un contexte paradoxal marqué par la domination sans partage de l'islam sunnite. Dans le domaine de l'imaginaire, l'auteur souligne les continuités entre l'antichiisme et l'antisémitisme, non seulement en raison des thèmes partagés par les deux répertoires mais aussi de la prévalence de thèses complotistes relatives à une alliance entre juifs et chiites pour anéantir l'islam. Une analyse des acteurs qui construisent et 
diffusent cet imaginaire montre un renouvellement significatif lié aux enjeux propres au contexte musulman français. Obsédés par la question de la pureté doctrinale et ennemis bien connus du chiisme, les salafistes jouent certes un rôle central mais ont été rejoints par des figures réformistes, c'est-à-dire proches de l'islam des Frères musulmans et notamment des idées d'un de leurs membres les plus influents dans l'espace musulman transnational, Yusuf al-Qardawi, Égyptien résidant au Qatar depuis les années 1960. Ennemis idéologiques du salafisme dont ils ne cessent de dénoncer l'influence, ils sont comparativement ouverts sur le plan doctrinal et pragmatiques dans leur conception des obligations religieuses qui incombent aux musulmans en contexte minoritaire. Depuis la guerre civile en Syrie et en Iraq, ils dénoncent l'expansion du chiisme moins sur la base d'arguments théologiques qu'en mobilisant des analyses le plus souvent géopolitiques qui associent chiisme, radicalisme, terrorisme et projet hégémonique mondial de l'Iran. Issus du monde laïc, ces nouveaux acteurs de l'anti-chiisme cherchent en réalité à consolider leur image de musulmans modérés afin de conforter leur autorité dans un champ musulman très concurrentiel. 